\title{
A Tomato Nucleotide Binding Sites-Leucine-Rich Repeat Gene Is Positively Involved in Plant Resistance to Phytophthora infestans
}

\author{
Ning Jiang, Jun Cui, Jun Meng, and Yushi Luan†
}

First, second, and fourth authors: School of Life Science and Biotechnology, Dalian University of Technology, Dalian, 116024, China; and third author: School of Computer Science and Technology, Dalian University of Technology, Dalian 116024, China. Accepted for publication 27 March 2018.

\begin{abstract}
The nucleotide binding sites-leucine-rich repeat (NBS-LRR) genes are key regulatory components of plant to pathogens. Phytophthora infestansinducible coding sequence encoding an NBS-LRR (SpNBS-LRR) protein in tomato (Solanum pimpinellifolium L3708) was cloned and characterized based on our RNA-Seq data and tomato genome. After sequence analysis, $S p$ NBS-LRR was identified as a hydrophilic protein with no transmembrane topological structure and no signal peptide. SpNBS-LRR had a close genetic relationship to RPS2 of Arabidopsis thaliana by phylogenetic analysis. In addition, $S p N B S-L R R$ gene was mainly expressed in root, with low expression observed in leaf and stem. To further investigate

the role of $S p N B S-L R R$ in tomato-P. infestans interaction, $S p N B S-L R R$ was introduced in susceptible tomatoes and three transgenic lines with higher expression level of $S p N B S-L R R$ were selected. These transgenic tomato plants that overexpressed $S p N B S-L R R$ displayed greater resistance than wild-type tomato plants after infection with $P$. infestans, as shown by decreased disease index, lesion diameters, number of necrotic cells, $P$. infestans abundance, and higher expression levels of the defense-related genes. This information provides insight into SpNBS-LRR involved in the resistance of tomato to $P$. infestans infection and candidate for breeding to enhance biotic stress-resistance in tomato.
\end{abstract}

Late blight, caused by the oomycete Phytophthora infestans, is one of the most devastating diseases of potato and tomato (Whisson et al. 2016). In the right environmental conditions, this disease can cause great losses in potato and tomato production (Axel et al. 2012; Fry et al. 2015; Sliwka 2004). Enormous economic damage amounting to an estimated $\$ 5$ billion worldwide annually is caused by $P$. infestans (Axel et al. 2012; Haverkort et al. 2009; Judelson and Blanco 2005). In tomato production, epidemics of late blight in the United States caused \$46 million and \$66 million economic losses of fresh market and processing tomatoes, respectively, in 2009 (Nowicki et al. 2012). Meanwhile, the total losses in processing tomato reached approximately 638,900 tons in China's main growing area, Bayannur city, the central and western part of Inner Mongolia in 2007 (Zhang et al. 2013). Because of the constant change of the global population of $P$. infestans and emergence of aggressive new strains, it is difficult to prevent and control late blight (Fry et al. 2015; Kamoun et al. 2015). There are still no effective methods thus far to control its damage due to the lack of understanding about the interaction mechanism between tomato and P. infestans. It is very urgent and significant that we study tomato resistance mechanisms against $P$. infestans and consider breeding $P$. infestansresistant tomato.

Plants evolve various mechanisms to protect themselves against the challenge of pathogens (Bhattarai et al. 2016; Chen et al. 2016; Dangl and Jones 2001). One of the efficient defense mechanisms is described by the gene-for-gene interaction between a host disease resistance $(\mathrm{R})$ gene and a pathogen avirulence (avr) gene (Chen et al. 2016; Flor 1956; Song et al. 2015). The NBS-LRR resistance genes

†Corresponding author: Y. Luan; E-mail: ysluan@dlut.edu.cn

Funding: This work is supported by grants from the National Natural Science Foundation of China grants 31471880 and 61472061.

*The $\boldsymbol{e}$-Xtra logo stands for "electronic extra" and indicates that seven supplementary figures and one supplementary table are published online.

(c) 2018 The American Phytopathological Society form the largest R-gene family among plant genomes, which encode proteins containing nucleotide binding sites (NBS) and leucine-rich repeat (LRR) domains (Ellis and Jones 1998; Zhao et al. 2016). It is believed that the NBS domain is involved in regulation of the signal conduction through conformational change (Inoue et al. 2013; Takken et al. 2006), whereas the function of the LRR domain is recognizing pathogens based on protein-protein interactions (Guo et al. 2016; Kobe and Kajava 2001). In Arabidopsis, the effectors avrB, avrRpt2, and avrPphB into plant leaves induces a defense response, which exclusively possess the corresponding NBS-LRR proteins RPM1, RPS2, and RPS5 (Gopalan et al. 1996; Leister et al. 1996; Warren et al. 1998).

Previous studies showed that some R genes encoding NBS-LRR proteins had characterized $N B S-L R R$ genes governing rice blast resistance (Pi64) (Ma et al. 2015), cotton Verticillium wilt resistance $(G b R V d)$ (Yang et al. 2016), tobacco resistance to $P$. parasitica (VaRGA1) (Li et al. 2017), wheat powdery mildew resistance (Pm3b and Pm8) (Hurni et al. 2013; Yahiaoui et al. 2004), and others. In the family Solanaceae, a large number of NBS-LRR-encoding genes were identified from their genomes (Qian et al. 2017; Wei et al. 2016). After the infection of pathogens such as tomato leaf curl New Delhi virus, Xanthomonas perforans, and Verticillium dahliae, NBS-LRR genes in tomato and potato expressed increased expression (Du et al. 2015; Kushwaha et al. 2015; Yang et al. 2015). Likewise, NBS$L R R$ genes could play crucial roles in the resistance of tomato and potato to $P$. infestans, potato virus $\mathrm{X}$, and other pathogens (Brommonschenkel et al. 2000; Cai et al. 2013; Sacco et al. 2007; van der Vossen et al. 2003).

In our previous work, we identified a lot of $N B S-L R R$ genes in tomato Solanum pimpinellifolium L3708 and S. lycopersicum Zaofen No.2 inoculated with $P$. infestans by analysis of the RNA-Seq data. The expression of these genes was increased after $P$. infestans infection. Here, we report that a $P$. infestans-inducible coding sequence (CDS) encoding an NBS-LRR ( $p p N B S-L R R)$ protein in tomato was cloned and characterized based on our RNA-Seq data and tomato genome. It has been submitted to the National Center for Biotechnology Information (NCBI) as GenBank number LC057399. To more thoroughly understand the function of $S p N B S-L R R$, transgenic 
tomato plants that overexpessed $S p N B S$ - $L R R$ were generated and assayed the resistance to $P$. infestans. The wild-type (WT) tomato plants displayed more serious disease symptoms than transgenic tomato plants overexpressed $S p N B S$ - $L R R$ after infection with $P$. infestans, as shown by higher disease index, increased number of necrotic cells, and lesion diameters. This study provides key clues in understanding the roles of $S p N B S$ - $L R R$ in tomato defense response to $P$. infestans.

\section{MATERIALS AND METHODS}

Plant and pathogen. S. pimpinellifolium L3708, a wild tomato species reported as possessing high resistance to a wide range of $P$. infestans isolates, was used as the material for clone and expression analysis of SpNBS-LRR. S. lycopersicum Zaofen No.2, which is susceptible to pathogens, was used as the material for transient expression and tomato transformation. The seeds were germinated at 28 to $30^{\circ} \mathrm{C}$. The plants were grown in the greenhouse at $25 \pm 3^{\circ} \mathrm{C}$ under $16 \mathrm{~h}$ light. Leaf tissue samples for gene clone were collected from 6-week-old L3708 tomato plants. P. infestans strain P12103 used in the experiments was provided by Professor Shan from Northwest A\&F University of China. It was maintained on oat medium at $20^{\circ} \mathrm{C}$ in dark (Luan et al. 2016).

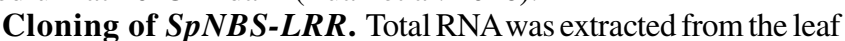
tissue samples with RNAiso Plus (TaKaRa, Dalian, China) following the manufacturer's instructions. The cDNA for molecular cloning was synthesized with reverse transcription M-MLV (TaKaRa).

A pair of primers for $S p N B S-L R R$ was designed by Primer Premier 5 Software based on tomato genome sequence (Sol$y c 02 g 036270$ ) and the information of RNA-Seq in our previous studies. The forward primer was with BamHI site and the reverse primer was with $\operatorname{SacI}$ site. The PCR system was $20 \mu$ volumes, which contained $1 \mu \mathrm{l}$ of cDNA, $1 \mu \mathrm{l}$ of forward primer $(10 \mu \mathrm{M}), 1 \mu \mathrm{l}$ of reverse primer $(10 \mu \mathrm{M}), 2 \mu \mathrm{l}$ of dNTP mixture ( $2.5 \mathrm{mM}$ each $), 2 \mu \mathrm{l}$ of 10× LA PCR buffer II ( $\mathrm{Mg}^{2+}$ Plus), $0.2 \mu \mathrm{l}$ of TaKaRa LA Taq, and $12.8 \mu \mathrm{l}$ of $\mathrm{ddH}_{2} \mathrm{O}$. The PCR amplification program used consisted of an initial denatured step at $94^{\circ} \mathrm{C}$ for $5 \mathrm{~min}, 32$ cycles at $95^{\circ} \mathrm{C}$ for $30 \mathrm{~s}$, $66^{\circ} \mathrm{C}$ for $30 \mathrm{~s}$, and $72^{\circ} \mathrm{C}$ for $3 \mathrm{~min}$, and a final elongation step at $72^{\circ} \mathrm{C}$ for $10 \mathrm{~min}$ performed with TaKaRa PCR Thermal Cycler Dice Gradient (TP600). Products after gel extraction purification were ligated with T-Vector pMD 19 (Simple) (TaKaRa) and then sequenced.

Sequence analysis. Sequence similarity analyses were performed using the BLAST program at NCBI (https://www.ncbi. nlm.nih.gov/blast). The CDS of $S p N B S-L R R$ was determined using BioEdit, and then translated into the corresponding amino acid sequence. The composition and physicochemical character, signal peptide, transmembrane topological structure, and hydrophobicity or hydrophilicity were analyzed by ProtParam at https://web. expasy.org/protparam, SignalP at http://www.cbs.dtu.dk/services/ SignalP, TMHMM at http://www.cbs.dtu.dk/services/TMHMM, and ProtScale at https://web.expasy.org/protscale. The multiple sequence alignment was performed using ClustalX 2 with the default settings. The domains were predicted by InterPro (http://www.ebi.ac. uk/interpro/scan.html). The logos of conserved domains were made by online software WebLogo (http://weblogo.berkeley.edu/logo.cgi). Phylogenetic trees were constructed using the neighbor-joining (NJ) and maximum likelihood (ML) method with Poisson correction by MEGA6.06.

Construction of overexpression plasmid and transient expression. The overexpression plasmid was constructed based on the pBI121 vector. The CDS of SpNBS-LRR was digested with $B a m \mathrm{HI}$ and $\mathrm{SacI}$ and then cloned into BamHI-SacI cut $\mathrm{pBI} 121$ vector, replacing the GUS gene under the control of cauliflower mosaic virus $35 \mathrm{~S}$ promoter. The recombinant plasmid was transformed into Agrobacterium tumefaciens strain GV3101 by freeze-thaw method (Höfgen and Willmitzer 1988).

A sample A. tumefaciens from culture was centrifuged at 4,000 $\mathrm{rpm} / \mathrm{min}$ and the sediment was resuspended by MMA (MES at
$10 \mathrm{mM}, \mathrm{AS}$ at $20 \mu \mathrm{M}$, and $\mathrm{MgCl}_{2}$ at $10 \mathrm{mM}$ ). Then, S. lycopersicum Zaofen No.2 epidermal cells were infected by A. tumefaciens. A. tumefaciens with empty vector was used as a control. After 0,1 , $2,3,4$, and 5 days, the infection areas of leaves were collected for RNA extraction. Then the infiltrated leaf regions were inoculated with $P$. infestans $\left(\sim 10^{6}\right.$ zoospores $\left./ \mathrm{ml}\right)$ and the number of disease spots was counted at 1,2,3,4, and 5 days postinoculation (dpi).

Generation of $S p N B S-L R R$ transgenic tomato lines and $P$. infestans resistance analysis. The cotyledon of tomato $S$. lycopersicum Zaofen No.2 were infected with A. tumefaciens strain GV3101 containing the modified plasmid pBI121-SpNBS$L R R$ via Agrobacterium-mediated leaf disk method. The resistant buds were selected on $1 / 2 \mathrm{MS}$ agar medium containing kanamycin at $25 \mathrm{mg} \mathrm{liter}^{-1}$ and carbenicillin disodium at $200 \mathrm{mg} \mathrm{liter}^{-1}$. After obtaining kanamycin-resistant plants, the presence of the transgene in the regenerating plantlets was further confirmed using PCR with neomycin phosphoryltransferase II ( $n p t \mathrm{II})$ gene specific primers $(\mathrm{Li}$ et al. 2015). The expression level of SpNBS-LRR in these selected positive transgenic lines was further examined by semiquantitative RT-PCR and quantitative RT-PCR (qRT-PCR), respectively.

Detached-leaf inoculation was performed according to the method of Li et al. (2015) with some modifications. The detached leaves from WT and transgenic tomato plants were inoculated with $20 \mu$ of $P$. infestans zoospore suspension $\left(\sim 10^{6}\right.$ zoospores $\left./ \mathrm{ml}\right)$ and then placed on filter paper in a petri dish. The whole plants were sprayed to run off with the same zoospore suspension. The inoculated leaves and whole plants were maintained in the dark at high humidity for 1 day at $20 \pm 1^{\circ} \mathrm{C}$, and then moved to the greenhouse at $20 \pm 1^{\circ} \mathrm{C}$ with a 16 -h light and 8 -h dark photoperiod cycle. After 5 days, the leaf symptoms were photographed and the diameter of lesion was measured. The diameter was measured using crossing method. The maximum and minimum length of the lesion were examined, respectively, and then, their average number was calculated as lesion diameter. Each experiment was carried out three times.

The leaf area occupied by blight lesions and stem area showing blight symptoms was estimated by the scale described by $\mathrm{Li}$ et al. (2015). Disease grades were categorized from 0 to 6 based on the lesion area: 0 , no symptoms; 1 , lesion area smaller than $5 \%$ of the total leaf area, no symptoms on the stem; 2, 5 to $15 \%$ of leaves area infected, no symptoms on the stem; 3,15 to $30 \%$ of leaves area infected, no symptoms on the stem; 4, 30 to $60 \%$ of leaves area infected and 10 to $30 \%$ of the stem are blighted; 5,60 to $90 \%$ of leaves area infected and 30 to $50 \%$ of the stem are blighted; and 6, larger than $95 \%$ leaves area infected and stem fully blighted or plant death. The resistance of a plant was indicated by the disease index (DI):

$$
\mathrm{DI}=\frac{\sum\left(D G_{i} \times n_{i}\right) \times 100}{n \times D G_{\text {imax }}}
$$

where $D G_{i}$ is the value of disease grades, $n_{i}$ is the number of plants with each disease grade, and $n$ is the total number of plants. Upon image acquisition, first the leaves were cut from tomato plants, and then the leaves were spread out on the white board smoothly and the images were captured using a camera. Last, the images were imported into ImageJ software to calculate the lesions, according to the introduction from the website (https://imagej.nih.gov/ij/). Each experiment was carried out three times.

In addition, the leaves were collected for the malonaldehyde (MDA) content detection and trypan blue staining assays, which were also performed as described by Li et al. (2015).

qRT-PCR analysis. The sequences of tomato $P R 1, P R 2$, and $P R 5$ were obtained from GenBank (Molinari et al. 2014). The GenBank accession numbers are Y08804, NM001247229, and NM001247422, respectively. The homolog sequences of Arabidopsis PDF1.2, Solyc04g072470 (PDF-like 1), and Solyc07g009260 (PDF-like 2) were downloaded from a tomato genome database 
(https://solgenomics.net) (Zai et al. 2015). The information of all primers is listed in Supplementary Table S1. qRT-PCR was performed with the SYBR PrimeScript miRNA RT-PCR kit (TaKaRa) according to the manufacturer's instructions using Corbett Rotor Gene 3000 qRT-PCR machine. The cDNA for qRT-PCR was obtained using PrimeScript RT Master Mix (TaKaRa). Tomato actin expression was used as a control. The data were analyzed by $2^{-\triangle \triangle \mathrm{Ct}}$ method.

\section{RESULTS}

The cloning, characterization, and expression analysis

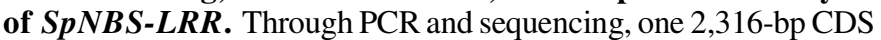
fragment (SpNBS-LRR) was cloned from S. pimpinellifolium L3708 and submitted to NCBI as GenBank accession number LC057399. It could encode a protein composed of 771 amino acids. The calculated molecular weight and theoretical pI of SpNBS-LRR are 87.4 and $5.74 \mathrm{kDa}$, respectively. The signal peptide prediction result shows that $S p$ NBS-LRR does not contains a signal peptide (Supplementary Fig. S1). This protein is hydrophilic because the grand average of hydropathicity (GRAVY) is -0.178 (Supplementary Fig. S2). The transmembrane topological structures of $S p$ NBS-LRR were predicted by TMHMM, and the result shows the peptide chains of $S p$ NBS-LRR outside the membrane, which indicates that it is not a transmembrane topological protein (Supplementary Fig. S3).
A BLAST search against the tomato genome showed that the putative $S p$ NBS-LRR sequence was most similar to the tomato NBS-LRR family. The identity of the amino acid sequence was 99\% similar to Solyc02g036270.2, a member of the NBS-LRR family. The domain analysis result showed this protein contains an NB-ARC domain, a coiled coil region, and a LRR region (Fig. 1A). The NBARC domain, located at 154 to 419 aa contained P-loop NTPases and AAA+ ATPase subdomain, and a coiled coil region and an LLR region were located at 427 to 447 aa and 460 to 757 aa, respectively (Fig. 1A).

The SpNBS-LRR sequence was aligned with ath_RPS2 and ath_RPP13 from Arabidopsis thaliana, ptc_RGH and ptc_RGH2 from Populus trichocarpa, sly_Tm-2 from $S$. lycopersicum, osa_NBS-LRR2 and osa_NBS-LRR1 from Oryza sativa, and cch_BS2 from Capsicum chacoense (Supplementary Fig. S4). The alignment revealed the motifs of NBS-LRRs were conserved, such as P-loop, kinase-2, and GLPL motifs (Supplementary Fig. S5). In addition, SpNBS-LRR belonged to CC-NBS-LRR subclass because of the existence of coiled coil region. In order to further determine the identity of the $S p N B S-L R R$, phylogenetic analysis was performed based on amino acid sequences using the NJ and ML methods, respectively. As shown in Figure 1B and Supplementary Figure S6, the $S p$ NBS-LRR had a close genetic relationship to $A$. thaliana RPS2, supported by high bootstrap values. Thus, we speculated the $S p$ NBS-LRR may have similar functions with RPS2 in plant-pathogen interaction pathway.
A

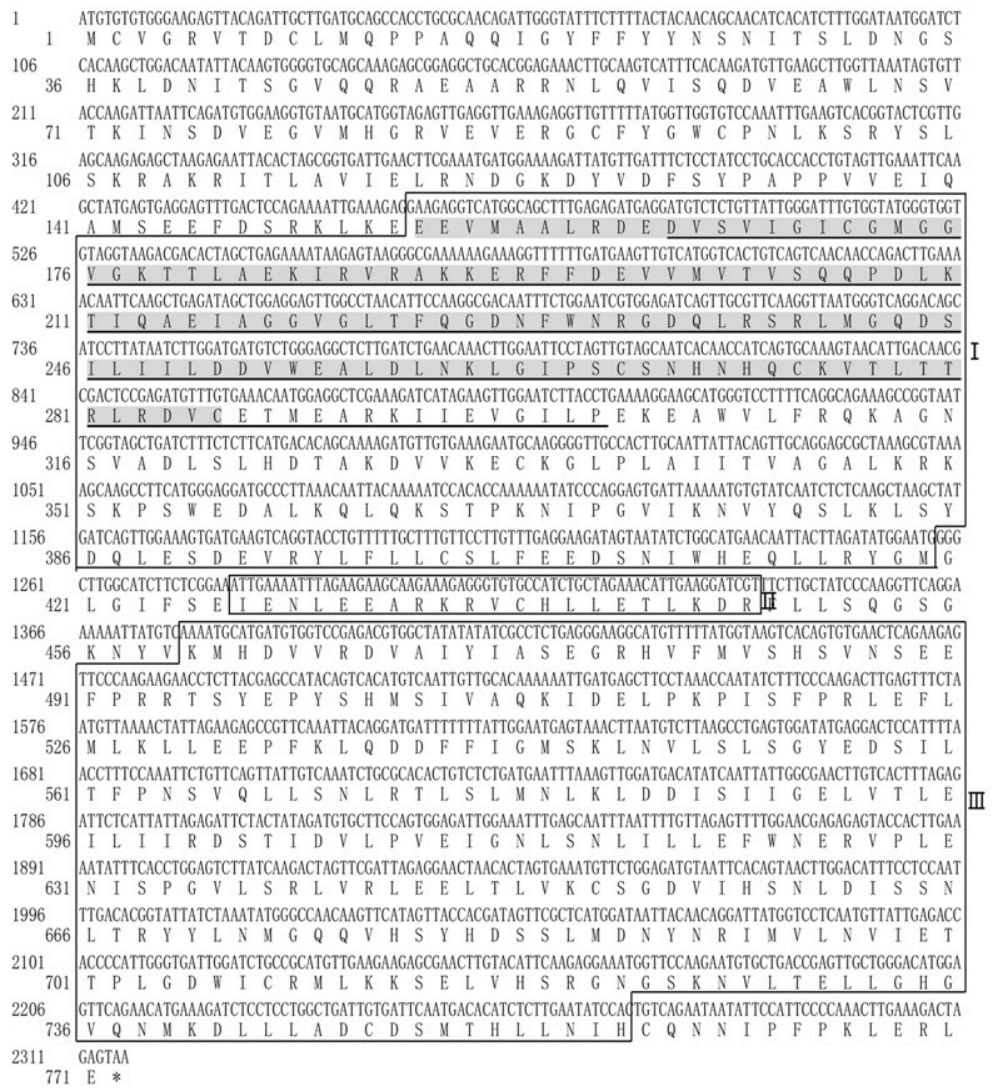

B
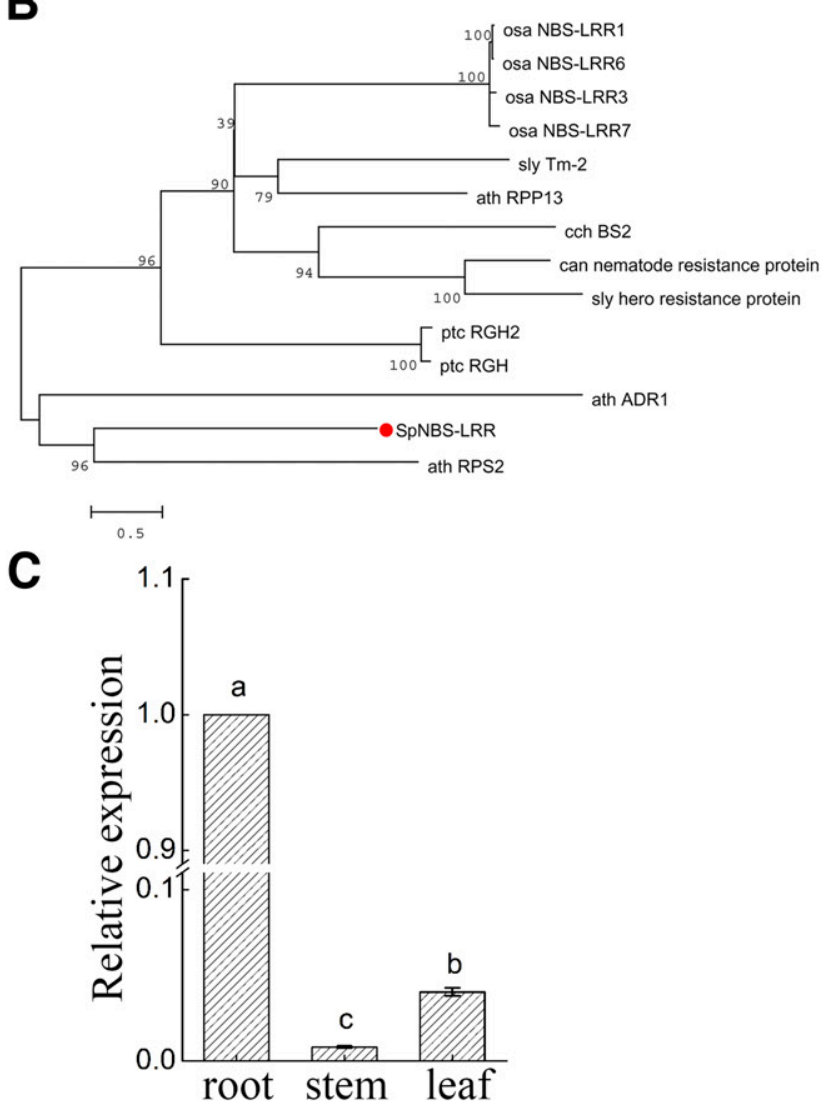

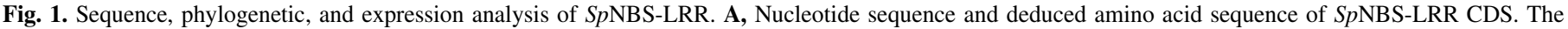

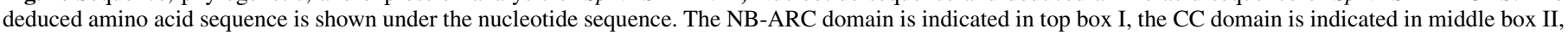

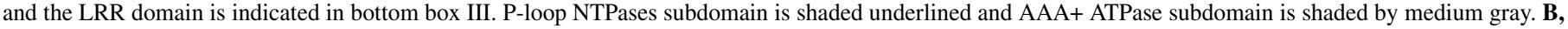

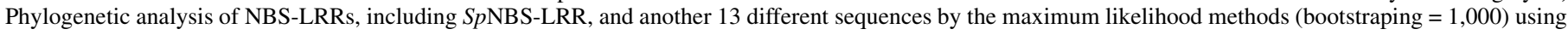

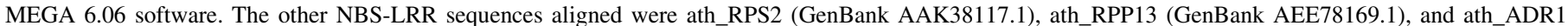

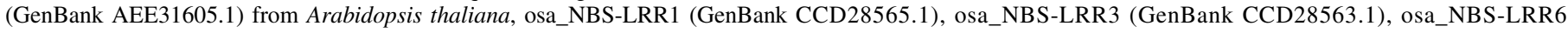

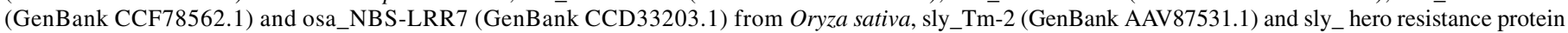

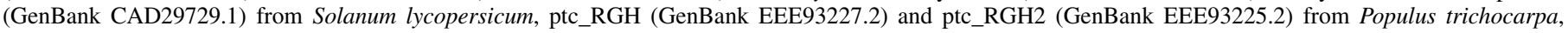

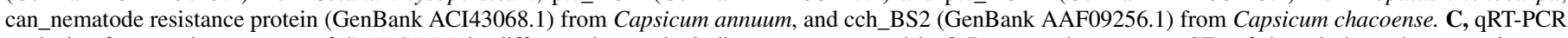

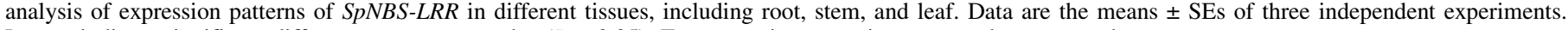
Letters indicate significant differences among samples $(P<0.05)$. Tomato actin expression was used as a control. 
The qRT-PCR was used to determine relative expression level of $S p N B S-L R R$ gene in three tomato tissues including root, leaf, and stem. The SpNBS-LRR gene was mainly expressed in root, with low expression observed in leaf and stem (Fig. 1C).

Construction of pBI-SpNBS-LRR plasmid and its overexpression by agrobacterium infiltration. To further investigate the role of $S p N B S-L R R$, a plasmid for the overexpression of $S p N B S-L R R$ was constructed on the basis of the pBI121 vector. The CDS of the SpNBS-LRR was cloned into BamHI-SacI cut pBI121, placing it under the control of the cauliflower mosaic virus $35 \mathrm{~S}$ promoter (Fig. 2A). Verified by restriction enzyme identification, PCR, and sequence analysis, the plasmid of pBI-SpNBS-LRR was successfully constructed. The pBI121-SpNBS-LRR plasmid was mobilized into A. tumefaciens strain GV3101 by the freeze-thaw method (Höfgen and Willmitzer 1988). As shown in Supplementary Figure S7B, the result of PCR proved that pBI121-SpNBS-LRR was successfully mobilized into GV3101. A. tumefaciens with and without SpNBS-LRR were introduced into leaves of S. lycopersicum Zaofen No.2 by agrobacterium infiltration. The qRT-PCR analysis showed that the expression level of $S p N B S-L R R$ was significantly up-regulated, reaching the highest point at 3 days after agrobacterium infiltration (Fig. 2B).

Three days after the transient overexpression of $S p N B S-L R R$, the leaves were infected with $P$. infestans. Resistance analysis showed that the extent of the disease was more severe and the lesions were significantly larger in control group than in the transientoverexpression-SpNBS-LRR group. As showed in Figure $2 \mathrm{C}$ and D, differences in the disease spots between control group and transientoverexpression-SpNBS-LRR group were not significant $(P<0.05)$ at 0 and $1 \mathrm{dpi}$. From $2 \mathrm{dpi}$, the average number of disease spots on the leaves overexpressing $S p N B S$ - $L R R$ was significantly less than that on the control group. These results suggested that transient overexpression of SpNBS-LRR may have enhanced the resistance of tomato against $P$. infestans.

SpNBS-LRR enhances the resistance of tomato to $P$. infestans. To investigate whether SpNBS-LRR is involved in tomato-P. infestans interaction, pBI121-SpNBS-LRR was introduced into tomato. After callus induction and shoot regeneration, 10 lines of transgenic tomato plants were confirmed by their abilities to form roots in medium containing kanamycin and PCR identification with neomycin phosphoryltransferase II (nptII) gene specific primers (Fig. 3A). The expression level of $S p N B S-L R R$ in these selected positive transgenic lines revealed that the transcript was the most in OE3, OE6, and OE8 (Fig. 3B). Meanwhile, the results of qRT-PCR analysis showed the expression level of SpNBS-LRR was approximately 10-fold, 12-fold, and 9-fold increased in OE3, OE6, OE8 compared with that in WT, respectively (Fig. 3C).

We first examined the disease phenotype using detached leaf inoculation assay. After inoculation with $P$. infestans, the disease symptoms were more severe on the leaves of WT compared with the disease symptoms on the leaves of SpNBS-LRR overexpressing lines. Trypan blue staining showed that the number of dead cells on the leaves of OE3, OE6, and OE8 was significantly less than the number on the WT, and the lesion diameter was also significantly smaller in transgenic lines (Fig. 3D and E).

In the whole-plant inoculation assay, the leaf area occupied by blight lesions was clearly more pronounced in WT at 5 dpi (Fig. 4A). The disease index (DI) also was scored at 5 dpi. A lower DI in transgenic lines was observed compared with that in WT plants (Fig. 4B). The transcript levels of $P$. infestans Actin gene were used to indicate $P$. infestans growth in plant by qRT-PCR (Jiang et al. 2016) and the abundance of $P$. infestans was significantly increased in WT compared with the transgenic lines (Fig. 4C). After trypan blue staining, darker blue marks in inoculated leaves indicated the cell death was more prominent in WT than in transgenic lines (Fig. 4D). In addition, MDA is widely recognized as an indicator of lipid peroxidation about membrane damage (Li et al. 2015). After inoculation, the accumulations of MDA content were significantly lower in the transgenic lines than in WT, suggesting transgenic plants did not suffer from severe membrane damage (Fig. 4E). These results suggested to some extent that overexpression of $S p N B S-L R R$ in tomato resulted in an enhancement of its resistance to $P$. infestans.

The transcript levels of pathogenesis-related genes were also investigated by qRT-PCR in WT and transgenic lines. The genes $P R 1, P R 2$, and $P R 5$ were considered as markers for salicylic acid (SA)-dependent systemic acquired resistance (SAR) and plant defensin $(P D F)$ and are involved in response to jasmonic acid (JA). Compared with WT, the expression levels of all these genes were significantly increased in transgenic lines (Fig. 5).

\section{DISCUSSION}

Many plant-pathogen interactions are determined by the presence of resistance genes that enable plants to recognize pathogens

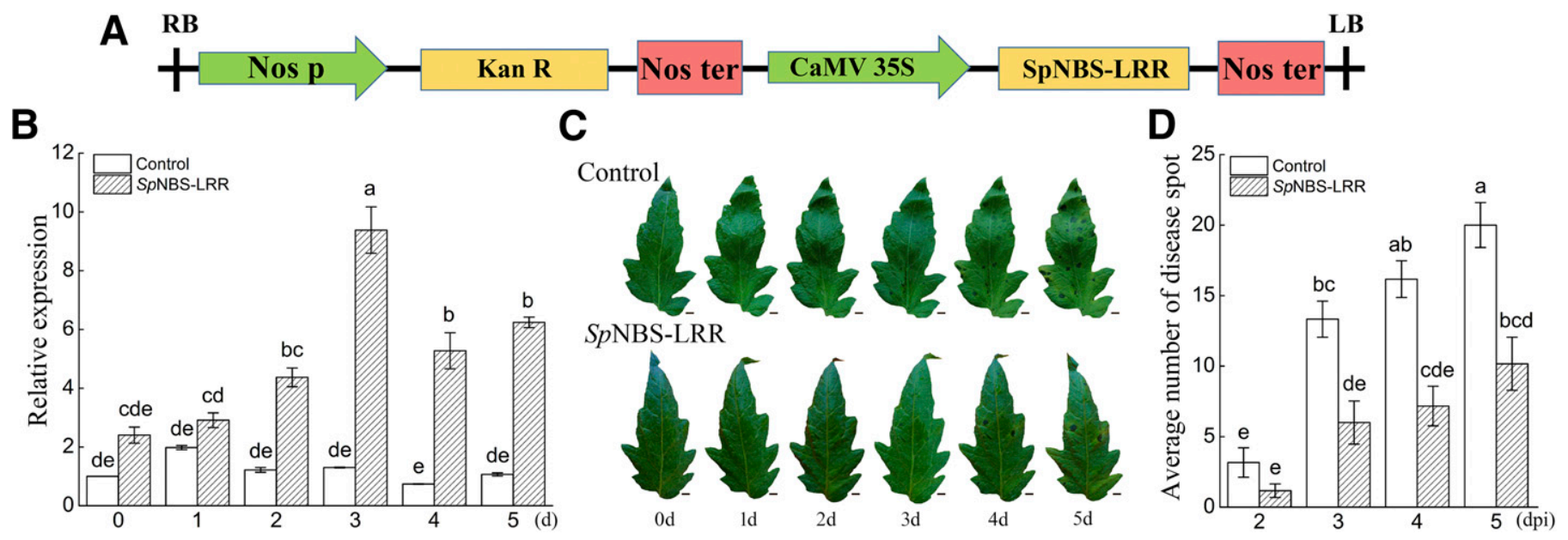

Fig. 2. Construction of 35S:SpNBS-LRR plasmid and transient overexpression of SpNBS-LRR in tomato leaves. A, Schematic representation of pBI121-SpNBS-LRR plasmid showing the sites for restriction enzymes. B, qRT-PCR validation of relative expression levels of $S p N B S$ - $L R R$ in control and transient-overexpressionSpNBS-LRR groups at $0,1,2,3,4$, and 5 days after agrobacterium infiltration. Error bars indicate standard error (SE; $n=3$ ) and letters indicate significant difference among samples $(P<0.05)$. Tomato actin expression was used as a control. $\mathbf{C}$, Leaf phenotypes of tomato leaves in control and transient-overexpressionSpNBS-LRR groups at 0 to 5 days after Phytophthora infestans inoculation. Scale bars $=0.5 \mathrm{~cm}$. D, Average number of disease spots on tomato leaves in control and transient-overexpression-SpNBS-LRR groups at 2,3,4, and 5 days postinoculation (dpi), respectively. Error bars indicate SE $(n=6)$ and letters indicate significant difference among samples $(P<0.05)$. 
and activate inducible defenses (Sekhwal et al. 2015). Previous studies on late blight showed that more than 60 potato resistance genes against $P$. infestans have been located, identified, and cloned (Rodewald and Trognitz 2013; Zhang et al. 2014). Compared with intensive studies on potato, those on late blight resistance in tomato are very limited (Zhang et al. 2014). Several resistance genes against $P$. infestans in tomato, such as $P h-1, P h-2, P h-3, P h-4$, and $P h-5$, have been reported and mapped on chromosome 7, 10, 9, 1, and 10, respectively (Black et al. 1996; Bonde and Murphy 1952; Foolad et al. 2008; Kim and Mutschler 2005; Merk et al. 2012). Our previous works focused on identification and functional analysis of tomato resistance genes (Li et al. 2015), miRNAs (Luan et al. 2015, 2016), and lncRNAs (Cui et al. 2017) associated with tomato resistance to $P$. infestans.

NBS-LRR proteins, the largest class of resistance proteins, have been established to play important roles in plant effector-triggered immunity. In this study, we isolated an NBS-LRR gene (SpNBS-LRR) associated with resistance to $P$. infestans from $S$. pimpinellifolium L3708. After inoculation of $P$. infestans, the SpNBS-LRR gene showed low-level expression at first and then rapidly increased in our previous works (Jiang et al. 2018). Similar to our previous results, de Vries et al. (2018) showed that the tomato NBS-LRRs (including Solyc02g036270) were responsive to $P$. infestans stress. A CC-NBS-
$L R R$ gene in the resistant Vitis riparia was expressed at a very low level under noninfected conditions; however, its transcript reached the highest level at $12 \mathrm{~h}$ postinoculation in response to Plasmopara viticola infection (Kortekamp et al. 2008).

Based on the results of phylogenetic analysis, this $S p$ NBS-LRR had a close genetic relationship to A. thaliana RPS2, supported by high bootstrap values (Fig. 1B). This showed that the $S p$ NBS-LRR maybe had similar functions with RPS2 in plant-pathogen interaction. In previous studies, RPS2 was involved in A. thaliana-Pseudomonas syringae DC3000 interaction (Cherkis et al. 2012; MacQueen et al. 2016). During interaction, RPS2 can bind the RIN4 and triggers ETI when RIN4 is cleaved by the bacterial effector AvrRpt2 (Axtell and Staskawicz 2003; Mackey et al. 2003). Two members of hypersensitive induced reaction protein (HIR) family, AtHIR1 and AtHIR2, form complexes with RPS2 in Arabidopsis, contributing to RPS2mediated ETI (Qi et al. 2011). In addition, another effector, AvrRpm1, also induces RPS2-dependent responses (Cherkis et al. 2012; Kim et al. 2009).

In tomato, 252 NBS-LRR genes were identified from the whole genome of $S$. lycopersicum, which were divided into six subgroups (Liu et al. 2014). In recent years, some tomato NBS-LRR genes were cloned and their functions were explored. An NBS-LRR resistance gene, $T m-2^{2}$, was cloned from tomato and verified its resistance to
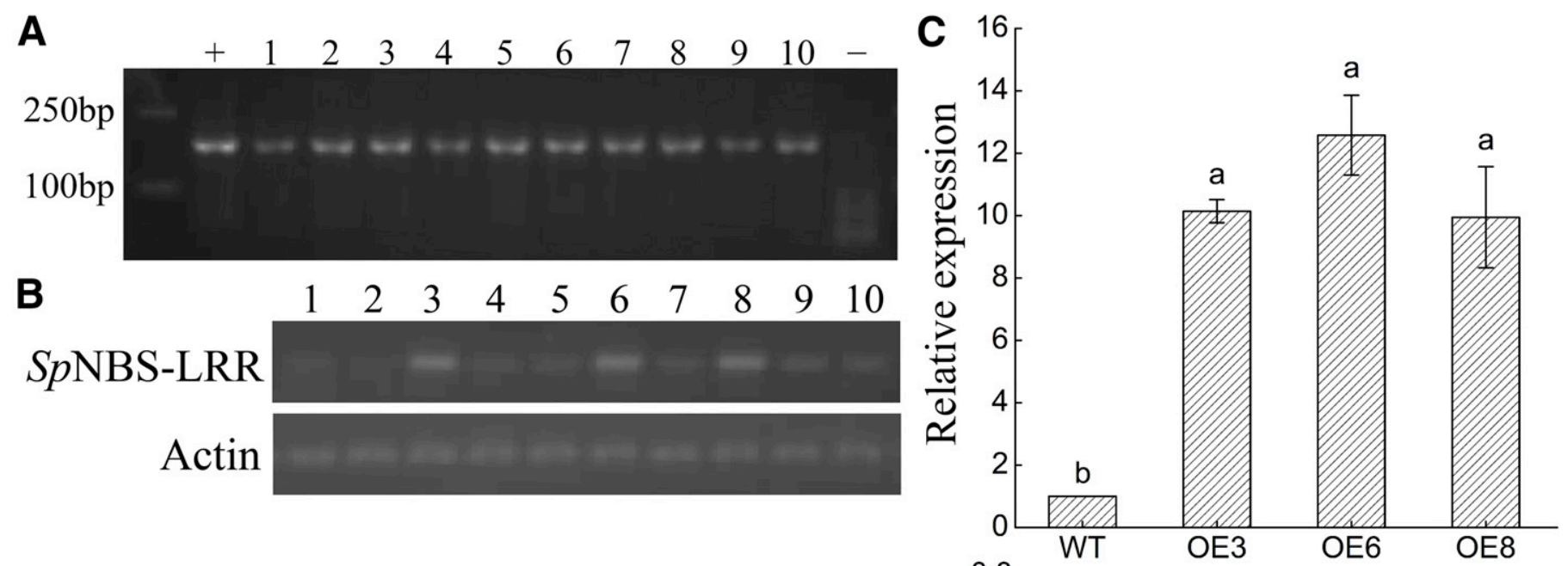

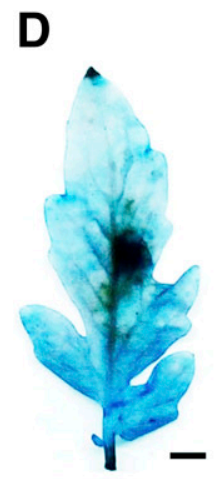

WT

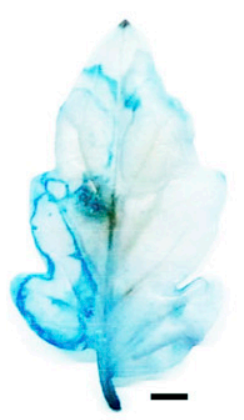

OE3

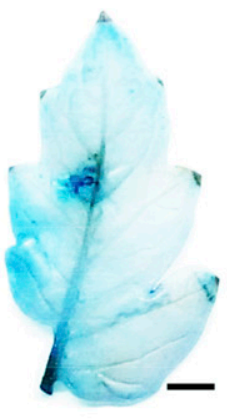

OE6

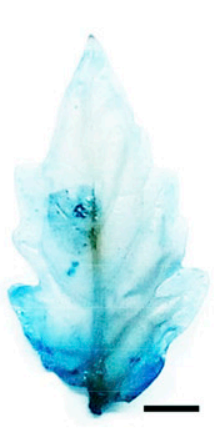

OE8

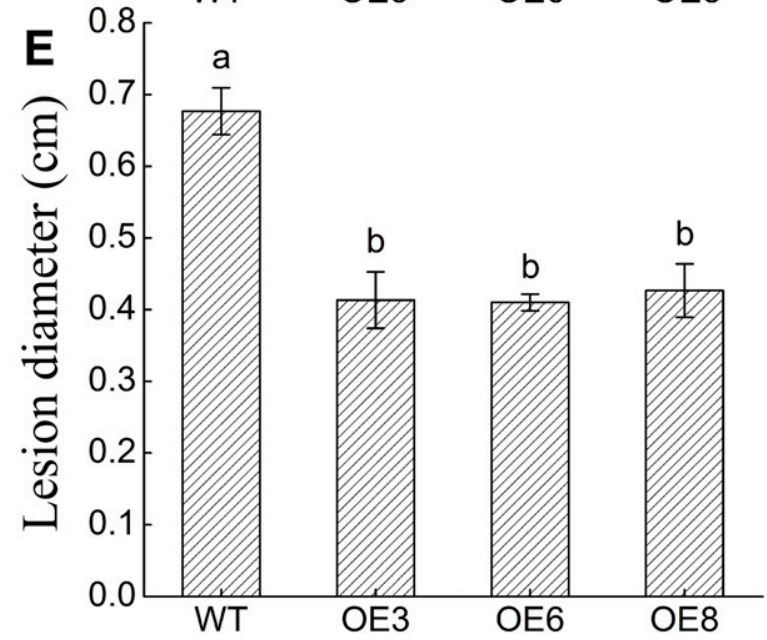

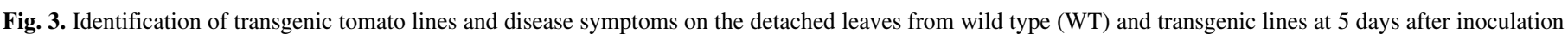

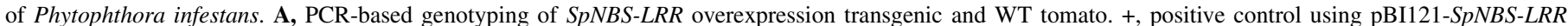

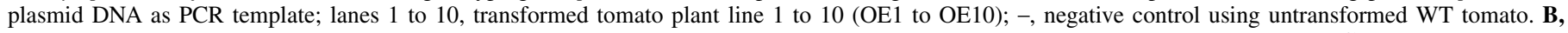

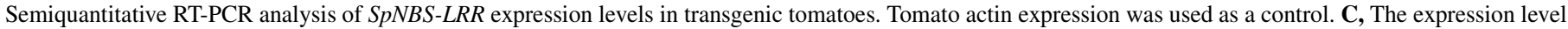

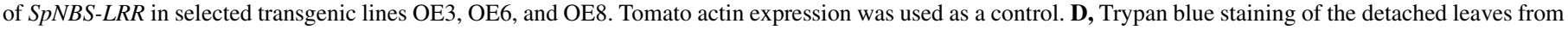

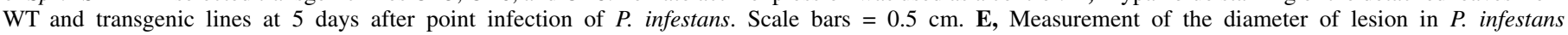

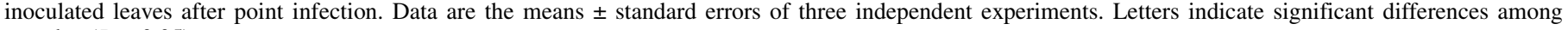
samples $(P<0.05)$. 
A

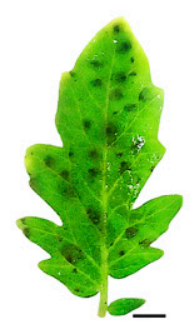

WT

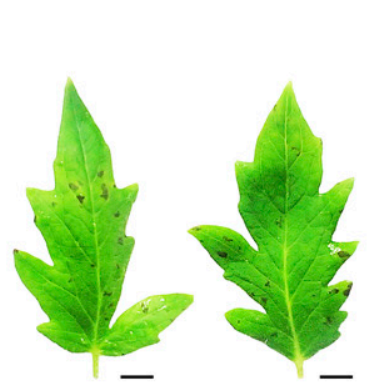

OE3
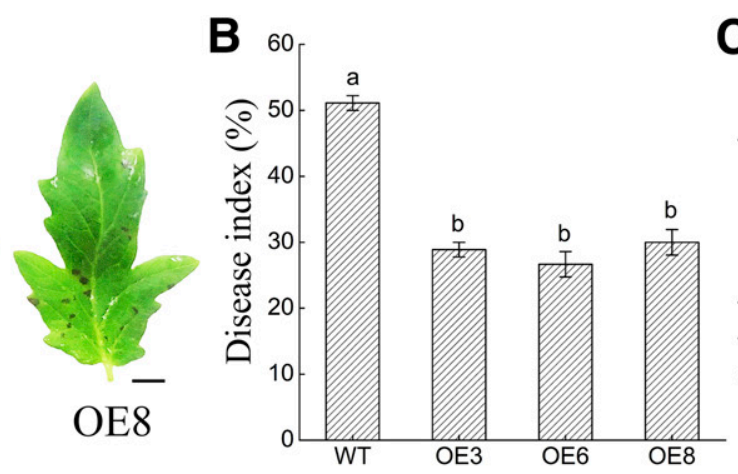

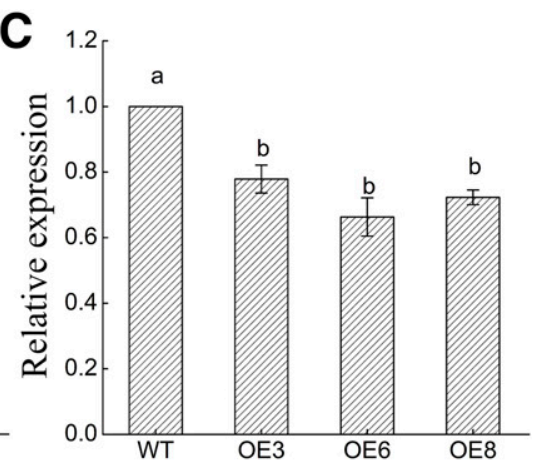

D

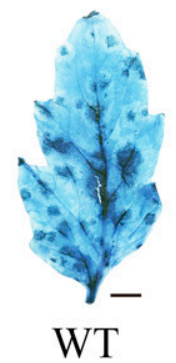

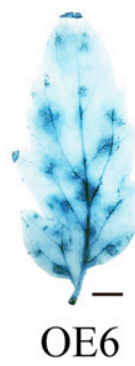

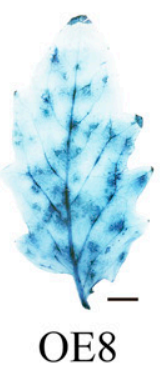

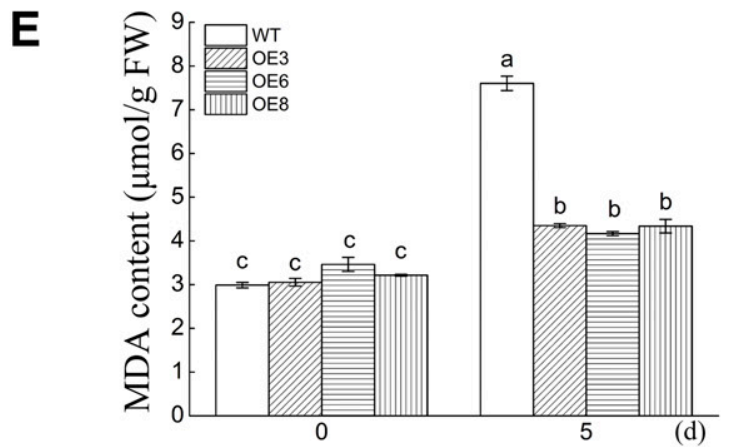

Fig. 4. Resistance of transgenic and wild type (WT) tomatoes after whole-plant inoculation with Phytophthora infestans. A, Disease symptoms on the leaves of WT and transgenic lines at 5 days postinoculation. Scale bars $=0.5 \mathrm{~cm}$. B, Disease index. C, Transcript accumulation of $P$. infestans Actin gene in these inoculated plants. Tomato actin expression was used as control. D, Trypan blue staining. Scale bars $=0.5 \mathrm{~cm}$. E, Malonaldehyde (MDA) content. Data are the means \pm standard errors of three independent experiments. Letters indicate significant differences among samples $(P<0.05)$.
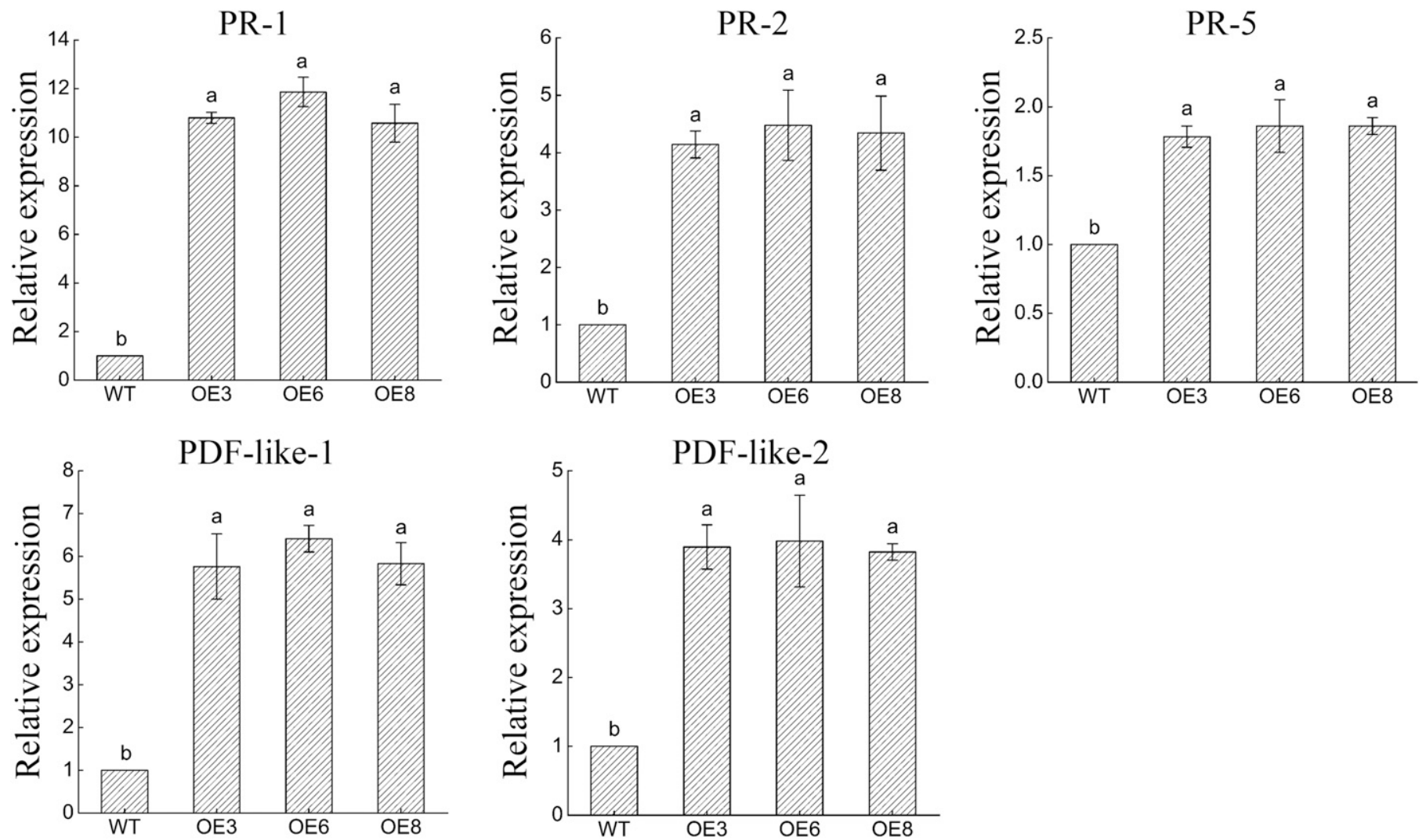

Fig. 5. Relative expression levels of some defense-related genes in the leaves of wild type (WT) and transgenic tomato plants. PR1, GenBank accession Y08804; PR2, GenBank accession NM001247229; PR5, GenBank accession NM001247422; PDF-like-1, Solyc04g072470; and PDF-like-2, Solyc07g009260. Data are the means \pm standard errors of three independent experiments. Letters indicate significant differences among samples $(P<0.05)$. Tomato actin expression was used as a control. 
tomato mosaic virus by transforming it to susceptible tomato plants (Lanfermeijer et al. 2003). Another member of tomato NBS$L R R$ gene family, $\operatorname{Prf}$, could enhance the resistance of tomatoes to $P$. syringae by associating with Pto (Gutierrez et al. 2010). The $P h-3$, encoding a CC-NBS-LRR protein, was isolated from $S$. pimpinellifolium by map-based cloning and demonstrated its resistance to $P$. infestans (Zhang et al. 2014). In addition, silencing of NBS-LRRs in tomato rendered it susceptible to Fusarium oxysporum (Ji et al. 2018; Ouyang et al. 2014). In this study, SpNBS-LRR was introduced into tomato S. lycopersicum Zaofen No.2, which is susceptible to $P$. infestans. Compared with untransformed WT plants, overexpression of $S p N B S-L R R$ increased $P$. infestans resistance in transgenic tomato plants, which was mainly demonstrated by decreased disease index, lesion diameters, number of necrotic cells, and $P$. infestans abundance (Figs. 3 and 4). This provides insight into $S p N B S$ - LRR and its involvement in the resistance of tomato to $P$. infestans.

Plants can be induced to switch on defense reactions to a broad range of pathogens as a result of prior exposure to pathogens. Induced resistance is expressed locally, at the site of the infection or systemically, at sites remotely located from the initial infection (Métraux et al. 2002). SAR and induced systemic resistance (ISR) are two forms of induced resistance (Choudhary et al. 2007). It has been shown that SAR and ISR are dependent on SA and JA signaling, respectively (Choudhary et al. 2007). Notably, PR1, PR2, and $P R 5$ are maker genes for SA signaling (Molinari et al. 2014), and Arabidopsis PDF1.2 are marker genes for JA signaling (Penninckx et al. 1996, 1998). Overexpression of a pepper PRl gene in tobacco plants enhanced resistance to $P$. nicotianae, Ralstonia solanacearum, and $P$. syringae pv. tabaci (Sarowar et al. 2005). Likewise, transgenic rice plants that overexpressed a $P D F$ gene, $R s-A F P 2$, showed enhanced resistance to two of the most important pathogens of rice, Magnaporthe oryzae and Rhizoctonia solani (Jha and Chattoo 2010). In this study, the expression levels of $P R 1, P R 2, P R 5$, and $P D F$ like (the homolog of Arabidopsis PDF1.2) genes were significantly increased in transgenic lines that overexpressed NBS-LRR (Fig. 5). Similarly, Pik-H4, an NBS-LRR protein interacting with OsBIHDlenhanced the accumulation of PR (Liu et al. 2017). These results suggest that NBS-LRR might induce the expression of $P R$ and $P D F$ genes and is involved in SAR and ISR in tomato-P. infestans interactions.

\section{LITERATURE CITED}

Axel, C., Zannini, E., Coffey, A., Guo, J., Waters, D. M., and Arendt, E. K. 2012. Ecofriendly control of potato late blight causative agent and the potential role of lactic acid bacteria: A review. Appl. Microbiol. Biotechnol. 96:37-48.

Axtell, M. J., and Staskawicz, B. J. 2003. Initiation of RPS2-specified disease resistance in Arabidopsis is coupled to the AvrRpt2-directed elimination of RIN4. Cell 112:369-377.

Bhattarai, K., Louws, F. J., Williamson, J. D., and Panthee, D. R. 2016. Differential response of tomato genotypes to Xanthomonas-specific pathogen-associated molecular patterns and correlation with bacterial spot (Xanthomonas perforans) resistance. Hortic. Res. 3:16035.

Black, L. L., Wang, T. C., Hanson, P., and Chen, J. T. 1996. Late blight resistance in four wild tomato accessions: Effectiveness in diverse locations and inheritance of resistance. (Abstr.) Phytopathology 86(suppl.):S24.

Bonde, R., and Murphy, E. F. 1952. Resistance of certain tomato varieties and crosses to late blight. Maine Agric. Exp. Stn. Bull. 497:5-15.

Brommonschenkel, S. H., Frary, A., Frary, A., and Tanksley, S. D. 2000. The broad-spectrum tospovirus resistance gene $S w-5$ of tomato is a homolog of the root-knot nematode resistance gene Mi. Mol. Plant-Microbe Interact. 13:1130-1138.

Cai, G., Restrepo, S., Myers, K., Zuluaga, P., Danies, G., Smart, C., and Fry, W. 2013. Gene profiling in partially resistant and susceptible near-isogenic tomatoes in response to late blight in the field. Mol. Plant Pathol. 14: 171-184.

Chen, X. R., Brurberg, M. B., Elameen, A., Klemsdal, S. S., and Martinussen, I. 2016. Expression of resistance gene analogs in woodland strawberry (Fragaria vesca) during infection with Phytophthora cactorum. Mol. Genet. Genomics 291:1967-1978.
Cherkis, K. A., Temple, B. R., Chung, E. H., Sondek, J., and Dangl, J. L. 2012. AvrRpm1 missense mutations weakly activate RPS2-mediated immune response in Arabidopsis thaliana. PLoS One 7:e42633.

Choudhary, D. K., Prakash, A., and Johri, B. N. 2007. Induced systemic resistance (ISR) in plants: Mechanism of action. Indian J. Microbiol. 47: 289-297.

Cui, J., Luan, Y., Jiang, N., Bao, H., and Meng, J. 2017. Comparative transcriptome analysis between resistant and susceptible tomato allows the identification of lncRNA16397 conferring resistance to Phytophthora infestans by co-expressing glutaredoxin. Plant J. 89:577-589.

Dangl, J. L., and Jones, J. D. G. 2001. Plant pathogens and integrated defense responses to infection. Nature 411:826-833.

de Vries, S., Kukuk, A., von Dahlen, J. K., Schnake, A., Kloesges, T., and Rose, L. E. 2018. Expression profiling across wild and cultivated tomatoes supports the relevance of early miR482/2118 suppression for Phytophthora resistance. Proc. Biol. Sci. 285:20172560.

Du, H., Wang, Y., Yang, J., and Yang, W. 2015. Comparative transcriptome analysis of resistant and susceptible tomato lines in response to infection by Xanthomonas perforans race T3. Front. Plant Sci. 6:1173.

Ellis, J., and Jones, D. 1998. Structure and function of proteins controlling strainspecific pathogen resistance in plant. Curr. Opin. Plant Biol. 1:288-293.

Flor, H. H. 1956. The complementary genic systems in flax and flax rust. Adv. Genet. 8:29-54.

Foolad, M. R., Merk, H. L., and Ashrafi, H. 2008. Genetics, genomics and breeding of late blight and early blight resistance in tomato. Crit. Rev. Plant Sci. 27:75-107.

Fry, W. E., Birch, P. R., Judelson, H. S., Grünwald, N. J., Danies, G., Everts, K. L., Gevens, A. J., Gugino, B. K., Johnson, D. A., Johnson, S. B., McGrath, M. T., Myers, K. L., Ristaino, J. B., Roberts, P. D., Secor, G., and Smart, C. D. 2015. Five reasons to consider Phytophthora infestans a reemerging pathogen. Phytopathology 105:966-981.

Gopalan, S., Bauer, D. W., Alfano, J. R., Loniello, A. O., He, S. Y., and Collmer, A. 1996. Expression of the Pseudomonas syringae avirulence protein AvrB in plant cells alleviates its dependence on the hypersensitive response and pathogenicity (Hrp) secretion system in eliciting genotypespecific hypersensitive cell death. Plant Cell 8:1095-1105.

Guo, C., Sun, X., Chen, X., Yang, S., Li, J., Wang, L., and Zhang, X. 2016. Cloning of novel rice blast resistance genes from two rapidly evolving NBS-LRR gene families in rice. Plant Mol. Biol. 90:95-105.

Gutierrez, J. R., Balmuth, A. L., Ntoukakis, V., Mucyn, T. S., Gimenez-Ibanez, S., Jones, A. M. E., and Rathjen, J. P. 2010. Prf immune complexes of tomato are oligomeric and contain multiple Pto-like kinases that diversify effector recognition. Plant J. 61:507-518.

Haverkort, A., Struik, P., Visser, R., and Jacobsen, E. 2009. Applied biotechnology to combat late blight in potato caused by Phytophthora infestans. Potato Res. 52:249-264.

Höfgen, R., and Willmitzer, L. 1988. Storage of competent cells for Agrobacterium transformation. Nucleic Acids Res. 16:9877.

Hurni, S., Brunner, S., Buchmann, G., Herren, G., Jordan, T., Krukowski, P., Wicker, T., Yahiaoui, N., Mago, R., and Keller, B. 2013. Rye Pm8 and wheat Pm3 are orthologous genes and show evolutionary conservation of resistance function against powdery mildew. Plant J. 76:957-969.

Inoue, H., Hayashi, N., Matsushita, A., Xinqiong, L., Nakayama, A., Sugano, S., Jiang, C. J., and Takatsuji, H. 2013. Blast resistance of CC-NB-LRR protein $\mathrm{Pb} 1$ is mediated by WRKY45 through protein- interaction. Proc. Natl. Acad. Sci. USA 110:9577-9582.

Ji, H. M., Zhao, M., Gao, Y., Cao, X. X., Mao, H. Y., Zhou, Y., Fan, W. Y., Borkovich, K. A., Ouyang, S. Q., and Liu, P. 2018. FRG3, a target of slmiR482e-3p, provides resistance against the fungal pathogen Fusarium oxysporum in tomato. Front Plant Sci. 9:26.

Jha, S., and Chattoo, B. B. 2010. Expression of a plant defensin in rice confers resistance to fungal phytopathogens. Transgenic Res. 19:373-384.

Jiang, N., Meng, J., Cui, J., Sun, G., and Luan, Y. 2018. Function identification of miR482b, a negative regulator during tomato resistance to Phytophthora infestans. Hortic. Res. 5:9.

Jiang, Y., Guo, L., Liu, R., Jiao, B., Zhao, X., Ling, Z., and Luo, K. 2016. Overexpression of poplar PtrWRKY89 in transgenic Arabidopsis leads to a reduction of disease resistance by regulating defense-related genes in salicylate-jasmonate-dependent signaling. PLoS One 11:e0149137.

Judelson, H. S., and Blanco, F. A. 2005. The spores of Phytophthora: weapons of the plant destroyer. Nat. Rev. Microbiol. 3:47-58.

Kamoun, S., Furzer, O., Jones, J. D., Judelson, H. S., Ali, G. S., Dalio, R. J., Roy, S. G., Schena, L., Zambounis, A., Panabières, F., Cahill, D., Ruocco, M., Figueiredo, A., Chen, X. R., Hulvey, J., Stam, R., Lamour, K., Gijzen, M., Tyler, B. M., Grünwald, N. J., Mukhtar, M. S., Tomé, D. F., Tör, M., Van Den Ackerveken, G., McDowell, J., Daayf, F., Fry, W. E., Lindqvist-Kreuze, H., Meijer, H. J., Petre, B., Ristaino, J., Yoshida, K., Birch, P. R., and Govers, F. 2015. The top 10 oomycete pathogens in molecular plant pathology. Mol. Plant Pathol. 16:413-434. 
Kim, M. G., Geng, X., Lee, S. Y., and Mackey, D. 2009. The Pseudomonas syringae type III effector AvrRpm1 induces significant defenses by activating the Arabidopsis nucleotide-binding leucine-rich repeat protein RPS2. Plant J. 57:645-653.

Kim, M. J., and Mutschler, M. A. 2005. Transfer to processing tomato and characterization of late blight resistance derived from Solanum pimpinellifolium L. L3708. J. Am. Soc. Hortic. Sci. 130:877-884.

Kobe, B., and Kajava, A. V. 2001. The leucine-rich repeat as a protein recognition motif. Curr. Opin. Struct. Biol. 11:725-732.

Kortekamp, A., Welter, L., Vogt, S., Knoll, A., Schwander, F., Töpfer, R., and Zyprian, E. 2008. Identification, isolation and characterization of a CC-NBSLRR candidate disease resistance gene family in grapevine. Mol. Breed. 22: 421-432.

Kushwaha, N., Singh, A. K., Basu, S., and Chakraborty, S. 2015. Differential response of diverse solanaceous hosts to tomato leaf curl New Delhi virus infection indicates coordinated action of NBS-LRR and RNAi-mediated host defense. Arch. Virol. 160:1499-1509.

Lanfermeijer, F. C., Dijkhuis, J., Sturre, M. J. G., de Haan, P., and Hille, J. 2003. Cloning and characterization of the durable tomato mosaic virus resistance gene Tm- $2^{2}$ from Lycopersicon esculentum. Plant Mol. Biol. 52:1039-1051.

Leister, R. T., Ausubel, F. M., and Katagiri, F. 1996. Molecular recognition of pathogen attack occurs inside of plant cells in plant disease resistance specified by the Arabidopsis genes RPS2 and RPM1. Proc. Natl. Acad. Sci. USA 93:15497-15502.

Li, J., Luan, Y., and Liu, Z. 2015. SpWRKY1 mediates resistance to Phytophthora infestans and tolerance to salt and drought stress by modulating reactive oxygen species homeostasis and expression of defense-related genes in tomato. Plant Cell Tissue Organ Cult. 123:67-81.

Li, X., Zhang, Y., Yin, L., and Lu, J. 2017. Overexpression of pathogeninduced grapevine TIR-NB-LRR gene VaRGAl enhances disease resistance and drought and salt tolerance in Nicotiana benthamiana. Protoplasma 254: 957-969.

Liu, H., Dong, S., Gu, F., Liu, W., Yang, G., Huang, M., Xiao, W., Liu, Y., Guo, T., Wang, H., Chen, Z., and Wang, J. 2017. NBS-LRR protein Pik-H4 interacts with OsBIHD1 to balance rice blast resistance and growth by coordinating ethylene-brassinosteroid pathway. Front. Plant Sci. 8:127.

Liu, Y., Wan, H., Wei, Y., Li, Z., Ye, Q., Wang, R., Ruan, M., Yao, Z., Zhou, G., and Yang, Y. 2014. Genome-wide analysis of NBS-LRR resistance genes in tomato. J. Nucl. Agric. Sci. 28:790-799.

Luan, Y., Cui, J., Wang, W., and Meng, J. 2016. MiR1918 enhances tomato sensitivity to Phytophthora infestans infection. Sci. Rep. 6:35858.

Luan, Y., Cui, J., Zhai, J., Li, J., Han, L., and Meng, J. 2015. High-throughput sequencing reveals differential expression of miRNAs in tomato inoculated with Phytophthora infestans. Planta 241:1405-1416.

Ma, J., Lei, C., Xu, X., Hao, K., Wang, J., Cheng, Z., Ma, X., Ma, J., Zhou, K., Zhang, X., Guo, X., Wu, F., Lin, Q., Wang, C., Zhai, H., Wang, H., and Wan, J. 2015. Pi64, encoding a novel CC-NBS-LRR protein, confers resistance to leaf and neck blast in rice. Mol. Plant-Microbe Interact. 28: 558-568.

Mackey, D., Belkhadir, Y., Alonso, J. M., Ecker, J. R., and Dangl, J. L. 2003. Arabidopsis RIN4 is a target of the type III virulence effector AvrRpt2 and modulates RPS2-mediated resistance. Cell 112:379-389.

MacQueen, A., Sun, X., and Bergelson, J. 2016. Genetic architecture and pleiotropy shape costs of Rps2-mediated resistance in Arabidopsis thaliana. Nat. Plants 2:16110.

Merk, H. L., Ashrafi, H., and Foolad, M. R. 2012. Selective genotyping to identify late blight resistance genes in an accession of the tomato wild species Solanum pimpinellifolium. Euphytica 187:63-75.

Métraux, J. P., Nawrath, C., and Genoud, T. 2002. Systemic acquired resistance. Euphytica 124:237-243.

Molinari, S., Fanelli, E., and Leonetti, P. 2014. Expression of tomato salicylic acid (SA)-responsive pathogenesis-related genes in Mi-1-mediated and SAinduced resistance to root-knot nematodes. Mol. Plant Pathol. 15:255-264.

Nowicki, M., Fooled, M. R., Nowakowska, M., and Kozik, E. U. 2012. Potato and tomato late blight caused by Phytophthora infestans: An overview of pathology and resistance breeding. Plant Dis. 96:4-17.

Ouyang, S., Park, G., Atamian, H. S., Han, C. S., Stajich, J. E., Kaloshian, I., and Borkovich, K. A. 2014. MicroRNAs suppress NB domain genes in tomato that confer resistance to Fusarium oxysporum. PLoS Pathog 10: e1004464.

Penninckx, I. A., Eggermont, K., Terras, F. R., Thomma, B. P., De Samblanx, G. W., Buchala, A., Métraux, J. P., Manners, J. M., and Broekaert, W. F. 1996. Pathogen-induced systemic activation of a plant defensin gene in Arabidopsis follows a salicylic acid-independent pathway. Plant Cell 8:2309-2323.
Penninckx, I. A., Thomma, B. P., Buchala, A., Métraux, J. P., and Broekaert, W. F. 1998. Concomitant activation of jasmonate and ethylene response pathways is required for induction of a plant defensin gene in Arabidopsis. Plant Cell 10:2103-2114.

Qi, Y., Tsuda, K., Nguyen, L. V., Wang, X., Lin, J., Murphy, A. S., Glazebrook, J., Thordal-Christensen, H., and Katagiri, F. 2011. Physical association of Arabidopsis hypersensitive induced reaction proteins (HIRs) with the immune receptor RPS2. J. Biol. Chem. 286:31297-31307.

Qian, L. H., Zhou, G. C., Sun, X. Q., Lei, Z., Zhang, Y. M., Xue, J. Y., and Hang, Y. Y. 2017. Distinct patterns of gene gain and loss: diverse evolutionary modes of NBS-encoding genes in three Solanaceae crop species. G3 (Bethesda) 7:1577-1585.

Rodewald, J., and Trognitz, B. 2013. Solanum resistance genes against Phytophthora infestans and their corresponding avirulence genes. Mol. Plant Pathol. 14:740-757.

Sacco, M. A., Mansoor, S., and Moffett, P. 2007. A RanGAP protein physically interacts with the NB-LRR protein $\mathrm{Rx}$, and is required for $\mathrm{Rx}-$ mediated viral resistance. Plant J. 52:82-93.

Sarowar, S., Kim, Y. J., Kim, E. N., Kim, K. D., Hwang, B. K., Islam, R., and Shin, J. S. 2005. Overexpression of a pepper basic pathogenesis-related protein 1 gene in tobacco plants enhances resistance to heavy metal and pathogen stresses. Plant Cell Rep. 24:216-224.

Sekhwal, M. K., Li, P., Lam, I., Wang, X., Cloutier, S., and You, F. M. 2015. Disease resistance gene analogs (RGAs) in plants. Int. J. Mol. Sci. 16: 19248-19290.

Sliwka, J. 2004. Genetic factors encoding resistance to late blight caused by Phytophthora infestans (Mont.) de Bary on the potato genetic map. Cell. Mol. Biol. Lett. 9:855-867.

Song, H., Wang, P. F., Li, T. T., Xia, H., Zhao, S. Z., Hou, L., and Zhao, C. Z. 2015. Genome-wide identification and evolutionary analysis of nucleotidebinding site-encoding resistance genes in Lotus japonicus (Fabaceae). Genet. Mol. Res. 14:16024-16040.

Takken, F. L., Albrecht, M., and Tameling, W. I. 2006. Resistance proteins: Molecular switches of plant defence. Curr. Opin. Plant Biol. 9:383-390.

van der Vossen, E., Sikkema, A., Hekkert, B., Gros, J., Stevens, P., Muskens, M., Wouters, D., Pereira, A., Stiekema, W., and Allefs, S. 2003. An ancient $R$ gene from the wild potato species Solanum bulbocastanum confers broadspectrum resistance to Phytophthora infestans in cultivated potato and tomato. Plant J. 36:867-882.

Warren, R. F., Henk, A., Mowery, P., Holub, E., and Innes, R. W. 1998. A mutation within the leucine-rich repeat domain of the Arabidopsis disease resistance gene RPS5 partially suppresses multiple bacterial and downy mildew resistance genes. Plant Cell 10:1439-1452.

Wei, C., Chen, J., and Kuang, H. 2016. Dramatic number variation of $R$ genes in Solanaceae species accounted for by a few $R$ gene subfamilies. PLoS One 11:e0148708.

Whisson, S. C., Boevink, P. C., Wang, S., and Birch, P. R. 2016. The cell biology of late blight disease. Curr. Opin. Microbiol. 34:127-135.

Yahiaoui, N., Srichumpa, P., Dudler, R., and Keller, B. 2004. Genome analysis at different ploidy levels allows cloning of the powdery mildew resistance gene Pm3b from hexaploid wheat. Plant J. 37:528-538.

Yang, J., Ma, Q., Zhang, Y., Wang, X., Zhang, G., and Ma, Z. 2016. Molecular cloning and functional analysis of GbRVd, a gene in Gossypium barbadense that plays an important role in conferring resistance to Verticillium wilt. Gene 575:687-694.

Yang, L., Mu, X., Liu, C., Cai, J., Shi, K., Zhu, W., and Yang, Q. 2015. Overexpression of potato miR482e enhanced plant sensitivity to Verticillium dahliae infection. J. Integr. Plant Biol. 57:1078-1088.

Zai, W., Ye, S., Miao, L., Xiong, Z., Zhang, H., Ma, Y., Li, Y., and Chen, Y. 2015. Genome-wide identification and expression analysis of defensin genes in tomato (Solanum lycopersicum). J. Agric. Biotechnol. 23: 1588-1596.

Zhang, C., Liu, L., Wang, X., Vossen, J., Li, G., Li, T., Zheng, Z., Gao, J., Guo, Y., Visser, R. G., Li, J., Bai, Y., and Du, Y. 2014. The $P h-3$ gene from Solanum pimpinellifolium encodes CC-NBS-LRR protein conferring resistance to Phytophthora infestans. Theor. Appl. Genet. 127:1353-1364.

Zhang, C. Z., Liu, L., Zheng, Z., Sun, Y. Y., Zhou, L. X., Yang, Y. H., Cheng, F., Zhang, Z. H., Wang, X. W., Huang, S. W., Xie, B. Y., Du, Y. C., Bai, Y. L., and Li, J. M. 2013. Fine mapping of the $P h-3$ gene conferring resistance to late blight (Phytophthora infestans) in tomato. Theor. Appl. Genet. 126:2643-2653.

Zhao, Y., Weng, Q., Song, J., Ma, H., Yuan, J., Dong, Z., and Liu, Y. 2016. Bioinformatics analysis of NBS-LRR encoding resistance genes in Setaria italic. Biochem. Genet. 54:232-248. 